\title{
COTAS NO SERVIÇO PÚBLICO FEDERAL: LEI 12.990/2014 E O SISTEMA AUTODECLARATÓRIO: LACUNAS LEGISLATIVAS E ANTINOMIAS EM RELAÇÃO AO SISTEMA JURÍDICO BRASILEIRO
}

\author{
E.A.R.OLIVEIRA* e M.F.S.TARGINO* \\ Instituto Federal de Educação, Ciência e Tecnologia da Paraíba \\ eduardoricarte@ hotmail.com* \\ fernandatargino@gmail.com
}

Submetido 07/08/2016 - Aceito 07/12/2012

DOI: $10.15628 /$ holos.2017.5073

\section{RESUMO}

O presente artigo consiste em uma análise crítica à Lei $12.990 / 2014$, que institui a política de cotas para negros nos concursos públicos da Administração Pública Federal. Nesse contexto, é estudada a Lei 12.228/2010, denominado de Estatuto da Igualdade Racial, essencial para a compreensão da legislação em questão. São averiguados alguns dados extraídos do IBGE acerca da população negra e de sua composição no serviço público federal. Analisa-se também o instituto da prescrição aplicado à Fazenda Pública, bem como o informativo no 512, do STJ, cotejando-os com o Decreto no 3.298/1999, o Decreto no 6.949/2009 e Lei no 7.853/1989, que, ao regulamentar os direitos da Pessoa Com Deficiência, também delimita situações de cotas. Pondera-se, por fim, algumas repercussões delituosas previstas tanto no Código Penal Brasileiro, como na Lei que define os crimes resultantes de preconceito de raça ou de cor.

PALAVRAS-CHAVE: Cotas, Lei 12.990/2014, Sistema autodeclaratório.

\section{QUOTAS IN THE FEDERAL PUBLIC SERVICE: LAW 12.990/2014 AND THE SYSTEM SELF-DECLARATORY: GAPS AND LEGISLATIVE ANTINOMIES IN RELATION TO THE BRAZILIAN LEGAL SYSTEM}

\begin{abstract}
This article consists of a critical analysis of the Law 12.990 / 2014 establishing the policy of quotas for blacks in public procurement of the Federal Public Administration. In this context, it is studied Law 12,228 / 2010 , called the Statute of Racial Equality, essential to understanding the legislation in question. It was realized an investigation some data extracted from IBGE about the black population and its composition in the federal public service. Also analyzed the prescription institute
\end{abstract}

applied to the State, as well as informative 512 , the Superior Court of Justice, comparing them with Decree 3,298 / 1999 , Decree 6,949 / 2009 and Law 7.853 / 1989 , that regulates the rights of Persons with Disabilities and also defines situations of quotas. It argues, finally, some criminal consequences provided for both the Brazilian Penal Code, as the law that defines crimes resulting from prejudice of race or color.

KEYWORDS: Quotas, Law 12.990/2014, System self-declaratory. 


\section{INTRODUÇÃO}

A inovação legislativa que prevê cotas para negros no serviço público federal deu-se através da Lei 12.990/2014. Desde logo se percebe uma série de entraves práticos na observância do referido dispositivo legal, que dificultam a sua aplicação de maneira isonômica e imparcial. Para que seja possível compreender a aplicação das cotas para concursos públicos da Administração Pública Federal em benefício dos candidatos que se autodeclararem pretos ou pardos é necessário conhecer a Lei 12.228/2010, intitulada Estatuto da Igualdade Racial, visto que a referida norma conceitua expressões-chave para a compreensão daquela legislação que agora se analisa.

Noutro aspecto, utilizando-se de alguns dados estatísticos acerca da população negra, extraídos do Censo 2010, elaborado pelo Instituto Brasileiro de Geografia e Estatística (IBGE), fazse uma análise a partir da exposição de motivos do Projeto de Lei no 6.738/2013, que originou a Lei $12.990 / 2014$, notadamente no que tange à parcela do serviço público federal composta por pessoas da raça negra. Serão tecidas algumas noções básicas acerca do instituto da prescrição, previsto no Código Civil, observando o seu marco para à Fazenda Pública, estipulado pelo Informativo no 512, do STJ. É trazida à tona a premissa da dívida cultural permanente que a população brasileira nutre em relação à etnia negra, motivado pela perpetuação da escravização dos pretos e pardos até o ano de 1888.

Essa concepção é suficiente para gerar distorções na previsão legal das referidas cotas, não só entre seus próprios artigos, como também em comparação com outras cotas previstas no nosso ordenamento jurídico, a exemplo das cotas estabelecidas para a inclusão de Pessoas Com Deficiência, consoante os Decretos no 3.298/1999 e no 6.949/2009 e a Lei no 7.853/1989, que possuem status constitucional, configurando norma supralegal, ou seja, hierarquicamente superior à Lei $12.990 / 2014$. Por outro lado, as referidas normas repercutem no Código Penal Brasileiro e na Lei que define os crimes resultantes de preconceito de raça ou de cor, prevendo tipos penais decorrentes do descumprimento às regras de reserva de vagas por etnia, o que tumultua ainda mais aplicação da famigerada Lei de cotas.

Não há mecanismo legalmente previsto que impeça a burla da norma apreço, possibilitando, sem maiores dificuldades, que pessoas sem quaisquer traços étnicos ou ascendência familiar com a raça se autodeclarem pretas ou pardas com o único intuito de se beneficiarem das cotas, incorrendo em deliberada fraude aos certames públicos. Por outro, ainda que anteveja a fraude, o agente público não pode se negar a dar posse ao candidato aprovado dentro das cotas, mesmo que seja evidente a ausência de traços fenotípicos de raça diversa, posto que incorreria no crime tipificado pelo art. 3으, da Lei no 7.716/1989.

A Lei 12.990/2014 não prevê mecanismos de aferição, não garante imunidade ao tipo penal acima delineado para os agentes públicos que avaliem se a autodeclaração é falsa ou não. $A$ despeito de a Secretaria de Gestão de Pessoas e Relações do Trabalho no Serviço Público, vinculada ao Ministério do Planejamento, Desenvolvimento e Gestão, haver editado a Orientação Normativa no 03, de 01 de Agosto de 2016, que dispõe sobre regras de aferição da veracidade da 
autodeclaração emanada por pessoas negras nos procedimentos de seleção pública, tal regramento não conseguiu solucionar as celeumas decorrentes destes casos.

O texto visa apenas a esclarecer os pontos polêmicos da Lei $\cong 12.990 / 2014$, fazendo uma comparação entre os dispositivos legais acima expostos, e trazendo à baila a discussão sobre a utilização do sistema de cotas atualmente previsto.

\section{REVISÃO BIBLIOGRÁFICA}

\subsection{Estatuto da igualdade racial}

A Lei $12.288 / 2010$, denominada de Estatuto da Igualdade Racial, implementou a política de igualdade racial, por meio da qual se justifica, ou melhor, tenta-se justificar, através de diversas ações afirmativas, um tratamento materialmente isonômico à etnia negra.

Referida norma traz algumas definições importantes para a sua interpretação, em especial, as previstas nos artigos 10 , 2ㅇ e 30 :

Art. 1ํ Esta Lei institui o Estatuto da Igualdade Racial, destinado a garantir à população negra a efetivação da igualdade de oportunidades, a defesa dos direitos étnicos individuais, coletivos e difusos e o combate à discriminação e às demais formas de intolerância étnica.

Parágrafo único. Para efeito deste Estatuto, considera-se:

I - discriminação racial ou étnico-racial: toda distinção, exclusão, restrição ou preferência baseada em raça, cor, descendência ou origem nacional ou étnica que tenha por objeto anular ou restringir o reconhecimento, gozo ou exercício, em igualdade de condições, de direitos humanos e liberdades fundamentais nos campos político, econômico, social, cultural ou em qualquer outro campo da vida pública ou privada;

II - desigualdade racial: toda situação injustificada de diferenciação de acesso e fruição de bens, serviços e oportunidades, nas esferas pública e privada, em virtude de raça, cor, descendência ou origem nacional ou étnica;

III - desigualdade de gênero e raça: assimetria existente no âmbito da sociedade que acentua a distância social entre mulheres negras e os demais segmentos sociais;

IV - população negra: o conjunto de pessoas que se autodeclaram pretas e pardas, conforme o quesito cor ou raça usado pela Fundação Instituto Brasileiro de Geografia e Estatística (IBGE), ou que adotam autodefinição análoga;

V - políticas públicas: as ações, iniciativas e programas adotados pelo Estado no cumprimento de suas atribuições institucionais; 
VI - ações afirmativas: os programas e medidas especiais adotados pelo Estado e pela iniciativa privada para a correção das desigualdades raciais e para a promoção da igualdade de oportunidades.

Art. $2^{\circ}$ É dever do Estado e da sociedade garantir a igualdade de oportunidades, reconhecendo a todo cidadão brasileiro, independentemente da etnia ou da cor da pele, o direito à participação na comunidade, especialmente nas atividades políticas, econômicas, empresariais, educacionais, culturais e esportivas, defendendo sua dignidade e seus valores religiosos e culturais.

Art. $3^{\circ}$ Além das normas constitucionais relativas aos princípios fundamentais, aos direitos e garantias fundamentais e aos direitos sociais, econômicos e culturais, o Estatuto da Igualdade Racial adota como diretriz político-jurídica a inclusão das vítimas de desigualdade étnico-racial, a valorização da igualdade étnica e o fortalecimento da identidade nacional brasileira.

Tais artigos regulamentam os conceitos de população negra, políticas públicas, desigualdade racial e ações afirmativas. Portanto, faz-se imprescindível a delimitação destes significados sob o prisma legal para que, analisando a regulamentação vigente em nosso ordenamento jurídico, seja possível analisar a temática aqui abordada.

Desde o Ensino Básico, aprendemos que a sociedade brasileira possui um débito com a população negra em razão da sua exploração como mão de obra motriz do desenvolvimento do Brasil. A construção básica do Estatuto da Igualdade Racial parte dessa premissa, defendida amplamente pela literatura nacional, com ilustra Santos:

A ideia de responsabilização pelos efeitos e danos gerados pela escravidão é antiga em nossa história. As atrocidades e privações impostas aos negros escravos e aos seus descendentes sempre suscitaram, nos mais diversos campos do saber, a ideia de reparação e de compensação pelos danos causados (SANTOS, 2007, p. 83)

Insta salientar, todavia, que a promulgação da Lei Áurea, oficialmente Lei Imperial n.o 3.353, sancionada em 13 de maio de 1888, extinguiu a escravidão no Brasil há 128 anos. Mais de um século se passou desde o fim da prática escravagista, mas o aludido débito ainda permanece, segundo os preceitos da norma em questão.

Assim, é oportuno questionar: quando se dará a quitação desta dívida? Se analisarmos a questão pela perspectiva jurídica, levando em conta o Informativo 512, do STJ, de 20 de fevereiro de 2013, tal débito estaria quitado nos 05 anos posteriores à abolição da escravatura. É o que explicitaremos no tópico seguinte, sob o aspecto do direito adjetivo.

2.2 Da prescrição contra a fazenda pública e da dívida eterna da sociedade brasileira com a população negra 
A doutrina entendia a prescrição como a perda do direito de ação, ocasião em que o direito de ação não era um direito independente, mas vinculado diretamente ao direito material que objetivava proteger.

Atualmente, em face da nova roupagem autônoma do Direito Processual, houve a diferenciação entre a ação e a pretensão. Nesse diapasão, Cunha tem excelentes ensinamentos:

O direito subjetivo, a partir de quando passa a ser exigível, dá origem à pretensão. De fato, a partir da exigibilidade do direito, surge ao seu titular o poder de exigir do obrigado a realização do direito, caracterizando a pretensão. Tal exigência, contudo, não comporta qualquer ação, de modo que o ao exercer pretensão o sujeito não age contra ninguém; apenas exige a realização do direto, limitando-se a aguardar a satisfaça por parte do destinatário.

Enquanto exercício da pretensão faz supor que o devedor, premido, atenda ao seu dever jurídico, a ação, uma vez exercida, consiste na prática de atos materiais voltados contra o sujeito passivo, independentemente do seu comportamento. Em outras palavras, no exercício da pretensão, o titular do direito apenas exige seu cumprimento, aguardando o correlato atendimento pelo obrigado. Já na ação, não há tal atitude passiva de espera do cumprimento, despontando, isto sim, a prática de atos conducentes à realização ou concretização do direito. (CUNHA, 2008, p. 68).

O viés principal da discussão sobre a distinção entre pretensão e ação versa puramente em razão do princípio da segurança das relações jurídicas. Assim, pretensões, em regra, não podem ser eternas e devem ser exercidas dentro de um prazo delimitado por lei. Esse prazo é justamente o que se define como prescrição.

O Código Civil de 2002 utiliza esta definição na disposição de seu art. 189: "Violado o direito, nasce para o titular a pretensão, a qual se extingue, pela prescrição, nos prazos a que aludem os arts. 205 e 206." (negritou-se)

Assim, pode-se concluir que se o direito material não for exercido através do direito potestativo à pretensão, dentro do prazo delimitado legalmente para tanto, o pleito estará prescrito. Portanto, o direito de ação subsiste, porém não mais poderá ser cobrado, em face do transcurso do lapso prescricional.

Assim, o tempo para se exigir determinada pretensão, mediante o direito de ação contra o Estado, diga-se, Fazenda Pública, é delimitado em 05 anos, segundo entendimento emanado pelo STJ - Superior Tribunal de Justiça em sede de julgamento de Recursos Repetitivos.

Sobre o tema, faz-se imperioso destacar o julgado relatado pelo ministro Mauro Campbell Marques, a Primeira Seção do Superior Tribunal de Justiça (STJ), de forma unânime, definiu que prescreve em cinco anos todo e qualquer direito ou ação movida contra a fazenda pública, seja ela federal estadual ou municipal, inclusive indenização por reparação civil. A decisão tem 
importância transcendental para nortear a atuação da advocacia pública foi abarcada pelo Informativo 512 do STJ:

ADMINISTRATIVO. RECURSO ESPECIAL REPRESENTATIVO DE CONTROVÉRSIA (ARTIGO 543-C DO CPC). RESPONSABILIDADE CIVIL DO ESTADO. AÇÃO INDENIZATÓRIA. PRESCRIÇÃO. PRAZO QUINQUENAL (ART. 1ㅇ DO DECRETO 20.910/32) X PRAZO TRIENAL (ART. 206, § 3, V, DO CC). PREVALÊNCIA DA LEI ESPECIAL. ORIENTAÇÃO PACIFICADA NO ÂMBITO DO STJ. RECURSO ESPECIAL NÃO PROVIDO. (REsp 1.251.993-PR, 1a Seção - Rel. Min. Mauro Campbell, julgado em 12/12/2012. - 2002 2013)

Assim, a noção de reparação aos danos causados pela sociedade brasileira contra a população negra, além de equivocada, por si só ocasiona uma segregação natural de raças, por transmitir a ideia de que a etnia negra não faria parte da própria sociedade brasileira. Nesse espeque, ainda é possível argumentar da maneira inversa: como a população afrodescendente iria pagar um débito consigo mesmo?

É uma noção muito confusa, mas que é bastante difundida e amplamente aceita sem entraves por toda a sociedade brasileira. Tornou-se uma espécie de dogma, qual seja, carregar eternamente o estigma do Brasil ter utilizado a mão-de-obra escrava até 1888 e, portanto, seremos eternamente culpados e devedores de um saldo negativo em relação à população negra, quando de sua submissão à escravidão, a extrema segregação social e de direitos.

Não se pode olvidar as atrocidades sofridas pela população negra em nosso país. É fato que subexistem preconceitos arraigados no seio da nossa sociedade, notadamente aqueles de origem racial. Mas será a estipulação de cotas para o ingresso no serviço público a ferramenta adequada para extirpar tais idiossincrasias sociais? Será possível promover a igualdade através da imposição de medidas segregadoras? Parece óbvio que a iniciativa promovida pela norma em apreço tende a gerar mais separação que conjugação, promovendo efeito inverso ao que pretende.

Na verdade, a Lei 12.288/2010 superlativa as diferenças entre grupos raciais, como se negros e brancos não fossem todos igualmente cidadão brasileiros, com os mesmo diretos e deveres legais e constitucionais. Vê-se bem o perfil separatista da norma em apreço quando prevê os direitos básicos à saúde e à educação para a população negra, repetindo direitos já garantidos, desde 1988, pela Carta Constitucional, para todas as pessoas, de maneira indistinta:

Art. 60 São direitos sociais a educação, a saúde, a alimentação, o trabalho, a moradia, o transporte, o lazer, a segurança, a previdência social, a proteção à maternidade e à infância, a assistência aos desamparados, na forma desta Constituição.

Art. 194. A seguridade social compreende um conjunto integrado de ações de iniciativa dos Poderes Públicos e da sociedade, destinadas a assegurar os direitos relativos à saúde, à previdência e à assistência social.

Parágrafo único. Compete ao Poder Público, nos termos da lei, organizar a seguridade social, com base nos seguintes objetivos: 
I - universalidade da cobertura e do atendimento;

Art. 205. A educação, direito de todos e dever do Estado e da família, será promovida e incentivada com a colaboração da sociedade, visando ao pleno desenvolvimento da pessoa, seu preparo para o exercício da cidadania e sua qualificação para o trabalho.

Art. 206. O ensino será ministrado com base nos seguintes princípios:

I - igualdade de condições para o acesso e permanência na escola;

A universalidade no atendimento, bem como a previsão do "direito de todos" destrói qualquer segregação de raças no texto constitucional. Logo, a ideia de tratamento divergente a determinado grupo racial como reparação pelos danos gerados pelo regime escravocrata, além de antiga e ultrapassada, não condiz com o texto constitucional. Inclusive desrespeita o postulado da segurança jurídica - corolário máximo de um Estado de Direto - uma vez que um débito cujo marco inicial de cobrança fora em 1888, com a Lei Áurea, ainda seria exigível em 2016.

Portanto, entendo não ser possível exigir tal débito nos dias atuais, considerando que a prescrição quanto à Fazenda Pública goza tão somente de 05 anos para exigibilidade. De maneira contrária, exigir atualmente tal débito seria estigmatizar as pessoas que se autodeclaram negros ou pardos e cobrar eternamente um famigerado débito através de ferramentas equivocadas, qual seja, a política de cotas.

Se realmente a educação e a saúde públicas fossem prestadas de acordo com a disposição constitucional, não seriam necessárias tais ferramentas segregadoras, utilizadas como subterfúgios para justificar uma inclusão social putativa.

\subsection{LEI 12.990/2014 E SUAS INCONSISTÊNCIAS}

A discussão versa basicamente acerca da reserva imediata para candidatos negros, no que tange ao art. 1으, § 1 ㅇ e 2 o da Lei 12.990/2014.

Art. 1 - Ficam reservadas aos negros $20 \%$ (vinte por cento) das vagas oferecidas nos concursos públicos para provimento de cargos efetivos e empregos públicos no âmbito da administração pública federal, das autarquias, das fundações públicas, das empresas públicas e das sociedades de economia mista controladas pela União, na forma desta Lei.

$\S 1$ ㅇ A reserva de vagas será aplicada sempre que o número de vagas oferecidas no concurso público for igual ou superior a 3 (três).

$\S 2$ 2 $\mathrm{Na}$ hipótese de quantitativo fracionado para o número de vagas reservadas a candidatos negros, esse será aumentado para o primeiro número inteiro subsequente, em caso de fração igual ou maior que 0,5 (cinco décimos), ou diminuído para número inteiro imediatamente inferior, em caso de fração menor que 0,5 (cinco décimos).

Um dos instrumentos de implementação desta política, foi à instituição de cotas para candidatos negros no âmbito do serviço público federal, por meio da Lei 12.990/2014. Neste 
panorama, a Presidência da República observou que a população de raça negra, no Brasil, correspondia a $50,74 \%$ de toda a população brasileira, portanto, a implantação do sistema de cotas para os concursos públicos federais seria de grande valia, uma vez que, as pesquisas de raça existentes nos bancos de dados do Poder Executivo da União apontam que a participação negra alcançaria apenas $30 \%$ do provimento dos cargos públicos no Poder Executivo Federal, consoante à própria exposição de motivos do Projeto Lei 6.738/2013, que deu origem à referida Lei (BATISTA, 2015).

Assim, o art. 10 da Lei 12.990/2014, criou a cota de $20 \%$ das vagas de concursos públicos federais no âmbito do Poder Executivo, destinando-as para os candidatos que se autodeclaram negros no ato da inscrição, consoante a previsão do art. $2 \stackrel{\text { ‥ }}{2}$

Porém, o $\S 1$ 10 primeiro, ao ser aplicado, perfaz um percentual de 33,33\% de reserva de vagas, ou seja, superior ao próprio caput do art. 1ำ, qual seja, 20\%. Uma sensível impropriedade na previsão legal e que supera, a título de exemplo, outras reservas legais existentes em nosso ordenamento jurídico.

Ponto interessante é uma reserva inicial e uma prioridade na convocação do candidato negro sobre o candidato PCD - Pessoa Com deficiência, ou seja, sobrepondo o Decreto 3.298/99, bem como a Lei no $7.853 / 89$ e o próprio Decreto $6.949 / 09$, que promulgou a Convenção Internacional sobre os Direitos das Pessoas com Deficiência, assinados em Nova York. A própria reserva inicial de vagas para os PCD's é estipulada entre os percentuais de $5 \%$ a $20 \%$ das vagas previstas nos certames.

Deparamo-nos com a seguinte situação, quando há conflito entre duas políticas afirmativas, qual delas deve ser aplicada em primeiro lugar? Deve-se observar um percentual maior na reserva de vagas prevista numa Lei Ordinária está sobrepondo um percentual estipulado por uma Convenção Internacional. Ressalto que a Convenção Internacional, quando não verse sobre direitos humanos e não possua o quórum de maioria absoluta em votação, deverá ter eficácia de norma supralegal, e não eficácia de Emenda Constitucional. Portanto, a Lei 12.990/2014 está, na prática, sobrepondo uma norma de eficácia supralegal, ou seja, uma norma de hierarquia inferior está sobrepondo uma norma de hierarquia superior.

Referido diploma normativo (Lei 12.990/2014), na mesma linha das Leis 12.288/2010 e 12.711/2012, até para evitar os debates biológicos, filosóficos e sociológicos, não previu requisitos objetivos, e muito menos subjetivos, para a prova da condição de negro, assim entendido o preto ou pardo. Estabeleceu apenas que devem ser considerados negros aqueles autodeclarados pretos ou pardos. É o teor do art. 2o da Lei 12.990/2014:

\section{Art. 2‥ Poderão concorrer às vagas reservadas a candidatos negros aqueles que se autodeclararem pretos ou pardos no ato da inscrição no concurso público, conforme o quesito cor ou raça utilizado pela Fundação Instituto Brasileiro de Geografia e Estatística - IBGE.}

Contudo, de fato, no parágrafo único do art. 2 ํㅡ Lei 12.990/2014, restou à disposição de que, se constatada declaração falsa, o candidato que se autodeclarara negro seria ser eliminado do certame, in verbis: 
Parágrafo único. $\mathrm{Na}$ hipótese de constatação de declaração falsa, o candidato será eliminado do concurso e, se houver sido nomeado, ficará sujeito à anulação da sua admissão ao serviço ou emprego público, após procedimento administrativo em que the sejam assegurados 0 contraditório e a ampla defesa, sem prejuízo de outras sanções cabíveis.

É com base neste dispositivo que as bancas examinadoras têm iniciado procedimentos de verificação da cor negra dos candidatos, defendendo que os critérios utilizados para o exame da cor seriam os mesmos do IBGE.

Contudo, duas inconsistências ainda persistem: I) a lei não especificou se constataria a falsidade e não elencou ferramentas para tal; II) o IBGE não possui critério externo para o exame de cor, uma vez que se utiliza exclusivamente do sistema de autodeclaração.

De maneira mais grave, há previsão legal no sentido de considerar crime a conduta de impedir ou obstar acesso de pessoa devidamente habilitada em qualquer cargo da Administração Direta, Indireta ou Concessionárias de Serviço Público, consoante art. º, da Lei no 7.716/1989:

Art. 3 Impedir ou obstar o acesso de alguém, devidamente habilitado, a qualquer cargo da Administração Direta ou Indireta, bem como das concessionárias de serviços públicos.

Parágrafo único. Incorre na mesma pena quem, por motivo de discriminação de raça, cor, etnia, religião ou procedência nacional, obstar a promoção funcional. (Incluído pela Lei no 12.288, de 2010) (Vigência)

Pena: reclusão de dois a cinco anos.

Além da Lei 12.990/2014 não especificar as ferramentas de aferição, não garante imunidade ao tipo penal acima delineado para os agentes públicos que avaliem se a autodeclaração é falsa ou não. De maneira paliativa, o Ministério do Planejamento, Desenvolvimento e Gestão Secretaria de Gestão de Pessoas e Relações do Trabalho no Serviço Público editou a Orientação Normativa no 03, de 01 de Agosto de 2016, que dispõe sobre regras de aferição da veracidade da autodeclaração prestada por candidatos negros para fins do disposto na Lei no 12.990, de 9 de junho de 2014.

Contudo, tal regulamentação apenas tangenciou sobre como deveria ser aferida a veracidade na autodeclaração dos candidatos ao prevê, em seu art. $2 \stackrel{0}{\circ}, \S 2 \stackrel{0}{ }$, a formação de uma comissão designada para tal fim:

$\S 2$ 2o - A comissão designada para a verificação da veracidade da autodeclaração deverá ter seus membros distribuídos por gênero, cor e, preferencialmente, naturalidade.

Percebe-se que a Orientação Normativa no 03, de 01 de Agosto de 2016 não enfrentou a questão do cometimento ou não de crime para o caso da referida comissão indeferir ou constatar falsa a autodeclaração dos candidatos inscritos para as referidas cotas. Também restou silente quanto ao tipo penal do art. 299, do Código Penal Brasileiro: 


\section{Falsidade ideológica}

Art. 299 - Omitir, em documento público ou particular, declaração que dele devia constar, ou nele inserir ou fazer inserir declaração falsa ou diversa da que devia ser escrita, com o fim de prejudicar direito, criar obrigação ou alterar a verdade sobre fato juridicamente relevante:

Pena - reclusão, de um a cinco anos, e multa, se o documento é público, e reclusão de um a três anos, e multa, se o documento é particular.

Se o candidato que se autodeclara como negro, contudo, não for considerando como tal pela banca ou pela comissão criada para tal avaliação, simplesmente poderá incorrer no tipo penal previsto pelo art. 299, do CP. Daí vem o estudo dos elementos do tipo penal, se o agente cometeu a conduta com dolo ou culpa.

Deste modo, temos uma aplicação da Lei 12.990/2014 complexa e falha. Uma Lei mal construída sob a análise dos prismas formal, hierárquico e constitucional, que pode ocasionar um aumento na segregação racial à qual, em tese, visa a combater. Ressalta-se o fato desta Lei possuir antinomias em relação a outras legislações vigentes, bem como ao fato desta norma possuir diversas lacunas, acarretando insegurança jurídica tanto para quem se submete ao sistema da autodeclaração, quanto para os servidores públicos, os quais aplicam o vergastado dispositivo legal.

O sistema de cotas passa uma falsa ideia de pagamento de um débito histórico entre raças, contudo, se for analisado sob o aspecto de exequibilidade de débito, o sistema jurídico vigente isenta a Fazenda Pública, dos débitos que excedam 05 anos de sua produção, ou seja, tal sistema possui um embasamento teórico na escravatura, que foi abolida em 1888, quando o Estado reconheceu que a escravidão deveria ser abolida, portanto, o marco inicial de que a Edilidade Pública gerou danos a uma coletividade. Assim, sob o prisma de demanda judicial, em tese, haveria prescrição para a reparação de danos no tocante ao direito processual.

\section{METODOLOGIA}

Trata-se de pesquisa bibliográfica e documental de natureza qualitativa. O levantamento teórico foi realizado por meio de livros, leis, periódicos e sites especializados. Fez-se uso de decisões jurisprudenciais, uma vez que por meio destas o Poder Judiciário brasileiro tem alargado o tratamento da matéria. Ademais, será aplicado o procedimento interpretativo, no intuito de analisar o conteúdo dos princípios jurídicos e dispositivos legais correlatos ao tema.

Por uma questão de método, o trabalho foi desenvolvido levando em consideração a dicotomia direito material/direito público. Isto porque, num primeiro momento, se vislumbra o objeto material perseguido, para em seguida, pesquisar sobre a eficácia jurídica e a sua aplicabilidade. 


\section{CONCLUSÃO}

Conforme fartamente explanado em linhas anteriores, reitera-se que a Lei 12.990/2014, da maneira como está posta atualmente, é imprecisa e lacunosa, apresentando diversas antinomias com o ordenamento jurídico brasileiro, notadamente com a própria Constituição da República Federativa do Brasil de 1988.

Trata-se de uma Lei que ignora a hierarquia das normas e que pode favorece a um aumento da segregação racial a qual, teoricamente, visa a combater. Sua aplicação ainda propaga a insegurança jurídica tanto para quem se submete ao sistema da autodeclaração, quanto para os servidores públicos que lidam com o provimento de cargos públicos, que precisam fazer uma verdadeira ginástica mental e moral para garantirem a aplicação da norma, a despeito repetidos casos de burla. Assim, percebe-se que o tema demanda uma urgente análise pormenorizada por parte do poder público, averiguando-se a adequação social da norma em apreço.

É oportuno ponderar se o advento da norma em apreço não tem gerado mais segregação racial do que inclusão do grupo pretende incluir, assim como se ela está dotada dos mecanismos necessários para Ihe garantirem uma aplicação eficaz, não só para evitar a nulificação do referido mecanismo, mas, ainda, para se evitar a insegurança jurídica, a ilegalidades e o próprio abarrotamento do já assoberbado Poder Judiciário com matérias que poderiam ser resolvidas antecipadamente pelo próprio Poder Legislativo, no processo de elaboração das normas.

\section{REFERÊNCIAS}

BATISTA, Hugo Fidelis. Concurso público: verificação da condição de candidato negro. Revista Jus Navigandi, Teresina, ano 20, no 4481. Recuperado em 8 outubro 2016, de https://jus.com.br/artigos/42312

BRASIL. Constituição (1988). Constituição da República Federativa do Brasil de 1988. Recuperado em 06 outubro de 2016, de http://www.planalto.gov.br/ccivil_03/constituicao/constituicaocompilado.htm

BRASIL. Decreto no 3.298, de 20 de dezembro de 1999. Recuperado em 06 outubro de 2016, de http://www.planalto.gov.br/ccivil_03/decreto/d3298.htm

BRASIL. Decreto no 6.949, de 25 de agosto de 2009. Recuperado em 06 outubro de 2016, de http://www.planalto.gov.br/ccivil_03/_ato2007-2010/2009/decreto/d6949.htm

BRASIL. Decreto-Lei no 2.848, de 07 de dezembro de 1940. Recuperado em 06 outubro de 2016, de http://www.planalto.gov.br/ccivil_03/decreto-lei/Del2848compilado.htm

BRASIL. Lei no 7.716, de 05 de janeiro de 1989. Recuperado em 06 outubro de 2016, de http://www.planalto.gov.br/ccivil_03/leis/L7716.htm

BRASIL. Lei no 7.853, de 24 de outubro de 1989. Recuperado em 06 outubro de 2016, de http://www.planalto.gov.br/ccivil_03/leis/L7853.htm

BRASIL. Lei no 10.406, de 10 de janeiro de 2002. Recuperado em 06 outubro de 2016, de http://www.planalto.gov.br/ccivil_03/leis/2002/L10406.htm 
BRASIL. Lei no 12.288, de 20 de julho de 2010. Recuperado em 06 outubro de 2016, de http://www.planalto.gov.br/ccivil_03/_ato2007-2010/2010/lei/l12288.htm

BRASIL. Lei no 12.711, de 29 de agosto de 2012. Recuperado em 06 outubro de 2016, de http://www.planalto.gov.br/ccivil_03/_ato2011-2014/2012/lei//12711.htm

BRASIL. Lei no 12.990, de 09 de junho de 2014. Recuperado em 06 outubro de 2016, de http://www.planalto.gov.br/ccivil_03/_Ato2011-2014/2014/Lei/L12990.htm

BRASIL. Projeto Lei no 6.738/2013, exposição de motivos que deu origem à Lei 12.990/2014. Recuperado em 06 outubro de 2016, de

http://www.camara.gov.br/proposicoesWeb/fichadetramitacao?idProposicao $=600255$

BRASIL. Instituto Brasileiro de Geografia e Estatística. Dados da Tabela 1.3.1., Resultados do Universo, do Censo Demográfico de 2010. Recuperado em 06 outubro de 2016, de

http://www.ibge.gov.br/home/estatistica/populacao/caracteristicas_raciais/notas_tecnicas.pdf

BRASIL. Superior Tribunal de Justiça. Informativo 512. Recuperado em 06 outubro de 2016, de https://ww2.stj.jus.br/jurisprudencia/externo/informativo/

CUNHA, Leonardo José Carneiro da. A Fazenda Pública em Juízo. 6ạ ed. São Paulo: Dialética, 2008.

SANTOS, Sales Augusto dos (Organizador). Ações Afirmativas e Combate ao Racismo nas Américas. Brasília: Ministério da Educação : UNESCO, 2007. 